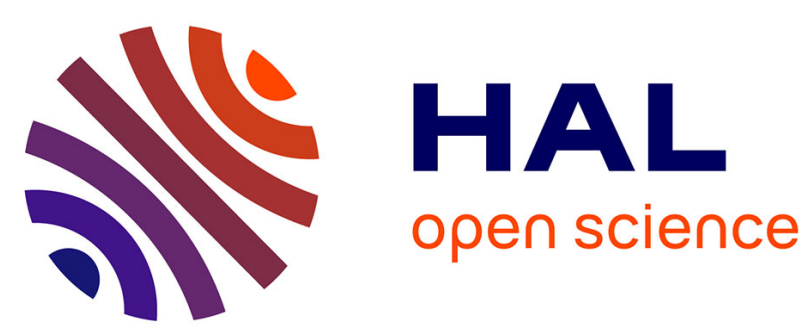

\title{
Profession and deception: Experimental evidence on lying behavior among business and medical students
}

Damien Besancenot, Radu Vranceanu

\section{To cite this version:}

Damien Besancenot, Radu Vranceanu. Profession and deception: Experimental evidence on lying behavior among business and medical students. 2020. hal-02937998

\section{HAL Id: hal-02937998 \\ https://essec.hal.science/hal-02937998}

Preprint submitted on 14 Sep 2020

HAL is a multi-disciplinary open access archive for the deposit and dissemination of scientific research documents, whether they are published or not. The documents may come from teaching and research institutions in France or abroad, or from public or private research centers.
L'archive ouverte pluridisciplinaire HAL, est destinée au dépôt et à la diffusion de documents scientifiques de niveau recherche, publiés ou non, émanant des établissements d'enseignement et de recherche français ou étrangers, des laboratoires publics ou privés. 


\section{ESSEC \\ BUSINESS SCHOOL}

\section{PROFESSION AND DECEPTION: EXPERIMENTAL EVIDENCE ON LYING BEHAVIOR AMONG BUSINESS AND MEDICAL STUDENTS}

Damien Besancenot

Radu Vranceanu

\section{ESSEC RESEARCH CENTER}

WORKING PAPER 2006

SEPTEMBER 2020 
September 11, 2020

\title{
Profession and deception: Experimental evidence on lying behavior among business and medical students*
}

\author{
Damien Besancenot $^{\dagger}$ and Radu Vranceanu ${ }^{\ddagger}$
}

\begin{abstract}
This paper reports data from a sender-receiver experiment that compares lying behavior between two groups of students, one in business administration and the other in medicine. We use a modified version of the sender-receiver deception game introduced by Erat and Gneezy (2012) to collect data on 393 subjects. The results show that both groups of students respond to incentives as expected: the frequency of lying is higher, the higher the benefit for the sender, and the lower the loss for the receiver is. For given payoffs, there is little difference between the two groups in the domain of white lies; however, business students resort to selfish lies more frequently than do medical students. Furthermore, the analysis does not confirm differences in altruism between the two groups.
\end{abstract}

JEL Classification: C91; D83; I19

Keywords: Lies, deception, communication, medicine, business administration, survey data.

${ }^{*}$ This is the preprint version of the paper published in the Journal of Economic Behavior and Organization, 2020, with DOI.ORG/10.1016/j.jebo.2020.08.47

${ }^{\dagger}$ University of Paris Descartes and LIRAES, 45 rue des Saints Pères, 75270 Paris. E-mail: damien.besancenot@parisdescartes.fr.

${ }^{\ddagger}$ Corresponding author. ESSEC Business School and THEMA. 1 Av. Bernard Hirsch, 95021 Cergy, France. E-mail: vranceanu@essec.edu. 


\section{Introduction}

Research on lying and deception has surged in the last fifteen years, driven by a rising awareness of how important dishonest communication can be in shaping economic and political outcomes, particularly in the era of unverifiable Internet news. In contrast to previous studies developed by psychologists on the motives and emotional consequences of false messages ${ }^{1}$ experimental economists have developed a set of studies emphasizing the material consequences of such ethically challenging behavior.

A fundamental typology of lies with respect to the material consequences of a lie in a sender-receiver game has been introduced by Erat and Gneezy (2012), following a pathbreaking paper in the research on lies by Gneezy (2005). ${ }^{2}$ In this setting, lies have a strategic purpose: the sender issues a false message with the aim of influencing beliefs and the actual response of the receiver. ${ }^{3}$ In general, the literature refers to a selfish black lie as a situation in which a false statement issued by the sender prompts the receiver to take an action that improves the well-being of the sender and deteriorates the well-being of the receiver. These selfish lies are ubiquitous in the world of business and are part of many commercial negotiations, with sellers overestimating costs, and buyers understating their true willingness to pay (Schweitzer and Croson, 1999; Aquino and Becker, 2005; Gneezy 2005; Chelliah and Swamy, 2018). Erat and Gneezy (2012) focus on the more ethically ambiguous white lies, where the false message is beneficial to the receiver, and further distinguish between Pareto white lies from which both the sender and the receiver benefit, and altruistic white lies,

\footnotetext{
${ }^{1}$ See Docan-Morgan (2019) for a synthesis of this research.

2 The classic theoretical framework for such games was laid out in the "cheap-talk" sender-receiver game by Crawford and Sobel (1982).

${ }^{3}$ Other studies focus on deception in a non strategic context. The most widespread task is the die-in-thecup game introduced by Fischbacher and Föllmi-Heusi (2013). When pay is related to performance and the latter cannot be observed, agents tend to exaggerate their performance, with significant heterogeneity among them (a nonnegligible fraction faithfully reports poor performance).
} 
whereby the sender sacrifices some of his/her benefit for the benefit of the receiver.

In this paper we compare the strategic lying behavior of two groups of people exposed to different professional norms and social expectations: students of business administration and students of medicine. While lying behavior of business students has already been analyzed by a number of studies, the lying behavior of medical students is unknown. The paper thus aims to contribute to both the literature on lying and deception and to a growing literature on behavioral health economics (Cox et al., 2016; Galizzi and Wiesen, 2018).

People who select into different professions have different motives and behave differently. Taking a simplified view, in the world of business, people are expected to pursue their own objectives with no restrictions other than the law, while the competitive market mechanism coordinates their self-interested choices towards the common interest. Individuals are expected to exploit any trading opportunity, and this is morally justified by the contribution to higher national wealth. Furthermore, rents of any sort can only be ephemeral, as competition should spread the benefit among the many (inter alia, Hayek, 1945; Von Misses, 1949). In this context, business people and students in business administration are supposed to embrace a materialistic mindset, endorsing a preference for competition, performance seeking and limited pro-sociality (Holland, 1985; Vansteenkiste et al., 2006). ${ }^{5} \quad$ Lies among traders who negotiate can be tolerated since, ultimately, competition guarantees the emergence of the market price at which social welfare is highest. Empirical research tends to corroborate these predictions about dishonest communication. McCabe and Trevino (1995) report higher self-reported frequencies of cheating on exams among undergraduate business than among students in other fields (including medical studies). ${ }^{6}$ Other studies suggest that students

\footnotetext{
${ }^{4}$ See Knight (1923) for a clear account of why this view is too narrow.

${ }^{5}$ Some lab experiments show that students in economics tend to be less cooperative in prisoners' dilemma (Frank et al. 1993, 1996).

${ }^{6}$ See also McCabe et al. (1995) reporting a higher self-reported propensity to engage in ethical misconduct
} 
in business and economics engage more easily in selfish lying than subjects in other fields, such as humanities or engineering (Lundquist et al., 2009; Lewis et al., 2012; López-Pérez and Spiegelman, 2019).

The medical profession is supposed to build on a fundamental moral principle - primum non nocere (first, do no harm) - a moral imperative that can be traced back at least to Epidemics (2, 4-7), the well-known book written by Hippocrates in 410 B.C. (Beauchamp and Childress, 1994; Hoerni, 2003). In line with this norm, it is widely believed that the medical profession attracts intrinsically motivated people with strong pro-social values (Brock et al., 2016), including a high degree of altruism or concern for patients' health (Arrow, 1963; Ellis and McGuire, 1986; Balsa and McGuire, 2003). However, the medical profession has its own flaws: a vast body of literature reveals that physicians respond to incentives like any other human being; furthermore, medical advice can be subject to conflicts of interest building on physicians' selfishness, a weakness that some large pharma can exploit to the expense of the patients or health insurance (Sah and Fugh-Berman, 2013; King and Bearman, 2017).

We consider two main hypotheses to be tested: (1) Because of their strong orientation towards competition and the winner-take-all norm of the profession, business students might be more tempted to tell selfish lies, in line with the results of previously cited studies comparing economics students with humanities and engineering students. On the other hand, medical students, following the do-no-harm principle and the higher ethical norms specific to their profession, might be less prone to telling selfish lies. (2) The degree of altruism is expected to be higher in the population of medical students. This could, in turn, explain a higher propensity to tell white lies among medical students.

The core task of our experiment is similar to that of Erat and Gneezy (2012) (or hereby MBA students than law students. 
inafter EG2012). There are a sender and a receiver, and two payment options, Option A and Option B, each providing specific payoffs to the two players. Only the sender knows the payoffs associated with each option. The receiver knows that there are payoffs associated with an Option A or B, but does not know what these payoffs are. At the onset of the game, the sender learns that the roll of a die issued a number, let us say 2. He/she can honestly convey the information to the receiver, or give him/her false information, i.e., disclose any other number between 1 and 6 . With this information, the receiver can select any number between 1 and 6 . If the selected number is the true number (i.e., 2), they both win the payoffs from Option A; otherwise, they both win the payoffs from Option B. As we explain later in more formal terms, in this game with a complex message space, a sender who assigns a probability of at least $1 / 6$ to the event that the receiver will follow his/her recommendation should tell the truth if he/she prefers Option A over Option B, and should lie in the opposite case. It is likely that the large majority of senders fall in this category.

We test for five conditions, each with its own set of payoffs, corresponding to an altruistic white lie, two Pareto white lies, and two selfish lies. Three of these conditions are exact replicas of Erat and Gneezy (2012), and two of them are different. These within-subject choices are made by one group of business students and one group of medical students. We also elicit (self-reported) risk tolerance and the degree of altruism by means of a charity giving task.

In brief, our results do not confirm the higher-altruism assumption for medical students compared to business students. With respect to lying behavior, medical students are not more prone to telling a white lie than business students. However, there is a substantial difference between the two populations in the domain of selfish lies; the frequency of selfish lies is $20 \%$ higher in the population of business students than in the population of medical 
students. This lie-specific difference in lying behavior might be explained by business and medical students differing not in their own perceptions of right and wrong, but in their beliefs about what the other members of their group believe to be right or wrong (Spiegelman, 2020). In this context, business and medical students can have the same aversion to white lies, yet business students, unlike medical students, could consider selfish lies to be normal practice within their profession.

The participants in our experiment are first-year students in French business and medicine schools. Thus, the experiment tests the preferences of the students who self-select into two different professions. It goes beyond the purpose of this paper to reveal all the motives that drive their decision. In a complementary analysis, we carry out a survey on a representative sample of the French population to capture the beliefs of the general public about the lying behavior of the two profiles of students. The results of the survey reveal significant coherence between the lying behavior observed in the lab and general opinion. A form of dynamic equilibrium, where beliefs drive students' of a given type towards a profession, and these career choices are validated by their behavior, could be one candidate mechanism for the observed behavior in the lab. A similar argument was submitted by Schneider et al. (2020) who reveal from lab data and national surveys in Switzerland that individuals who are least concerned with acting morally self-select into jobs generally perceived as immoral.

While students might identify with their future on-the-job decisions (Hennig-Schmidt et al., 2011), socialization through education (Rako et al., 2017; Spiegelman, 2020) and internalization of professional norms (Ahlert et al., 2012; Kestenrich et al., 2015) can alter preferences and thus shape the behavior of future professionals in the two fields. As a path for future research, it would be interesting to study whether our results hold in an experiment involving last-year students or professionals instead of first-year students. 
A known limitation of the within-subject design is that subjects might use information from early tasks in the experiment to second-guess and update their answers in later tasks. However, while this criticism may apply within one group of students, the analysis focuses essentially on the comparison between medicine and business students who were exposed to identical choices (in a between-subject setting). As a benefit of the within-subject design, we were able to elicit important subject characteristics such as altruism and risk tolerance and use them as controls in our analysis. We also ensured that we collected a relatively large number of observations to limit the measurement error problem.

\section{Review of literature}

A substantial body of evidence with elementary deception games has established that some persons resist the temptation to lie regardless of the potential benefits and that those who do lie do not push the lies to extreme limits, even if the subjects forgo positive gains by doing so. ${ }^{7}$ Furthermore, it has been shown that many people refrain from lying even if this action is beneficial to the receiver of the information (Erat and Gneezy, 2012; Cappelen et al., 2013; Biziou-van Pol et al., 2015). These results suggest that humans have some form psychological cost of lying, which could be grounded in the self-image of the person (Ellingsen and Johannesson, 2004; Gneezy, 2005; Vanberg, 2008; Gneezy, 2020) or in how others see him/her, whether directly in terms of reputation (Mazar et al. 2008; Tergiman and Villeval, 2019) or unfulfilled expectations (Charness and Dufwemberg, 2006; Dufwenberg and Dufwenberg, 2018; Gneezy et al., 2018; Khalmetski and Sliwka, 2019), or multiple combinations of these motives as analyzed in Abeler et al. (2019).

In the last few years, a substantial body of experimental research has emerged to test the extent of altruism among medical students. Hennig-Schmidt et al. (2011) use a lab experi-

\footnotetext{
7 See the surveys by Rosembaum et al. (2014), Jacobsen et al. (2018), Abeler et al. (2019) and the meta-analysis by Gerlach et al. (2019). As a caveat, in the experiments by Barcelo and Capraro (2019) and Gneezy et al. (2019), the proportion of liars who chose the extreme lie is nonetheless very large.
} 
ment to compare medical students' behavior under the fee-for-service (FFS) and capitation (CAP, which is a fixed payment per patient) models and find results that can be explained only if subjects present a substantial degree of concern about the patients' well-being. ${ }^{8}$ Godager and Wiesen (2013) use the data set from Hennig-Schmidt et al. (2011) to estimate the (positive) weight of patients' utility in the physician's own utility function. Martinsson and Persson (2019) show that the weight of patients' utility varies with the severity of the disease, itself related to the physician's system of priorities. While the assumption of physicians' altruism seems to be corroborated by this evidence, the question of whether physicians (or medical students) are more or less altruistic than individuals in other categories is still unsettled. Brosig-Koch et al. (2017) compare the decisions of medical students with those of business students in a similar experiment and find evidence that non-medical students are less altruistic albeit with significant heterogeneity. Ahlert (2012) compares the distributive preferences of medical and economics students and finds evidence that, in an unframed setting, economists choose more often the individualistic profit-maximizing allocation. In contrast with these results, Li et al. (2017) study choices in a standard dictator game and find no difference in altruism between medical students and the general population or similar law students.

There is substantial literature, surveyed in Searight and Meredith (2019) on the scale and scope of deceptive communication in physician-patient communication. These authors explain that traditionally, physicians tend to avoid blunt communication of bad news and often hide or attenuate it, even in cases in which truth-telling can actually improve the condition of the patient. ${ }^{9}$ Such behavior can be rationalized if prosocial lies are perceived

\footnotetext{
8 Altruism tempers overprovision under FFS and fosters undeprovision under CAP beyond what pure profit maximization would suggest.

${ }^{9}$ See also Iezzoni et al. (2012).
} 
as "more moral" than telling the truth (Levine and Schweitzer, 2014; Levine et al. 2018), or if physicians develop compassion with respect to the difficult situation of the patient (Lupoli et al., 2017).

Despite the obvious importance of these issues, experimental studies on lying behavior among physicians and medical students are rather scarce. As a notable exception, HennigSchmidt et al. (2018) built a framed experiment to analyze diagnosis-related group upcoding in neonatology, comparing the reporting by business and medical students. In the absence of audits and sanctions, overreporting (which leads to higher payoffs) is the dominant strategy (with $70 \%$ of participants engaging in overt dishonesty); furthermore, medical students appear to be more prone to overreporting than economics students (the trend, however, reverses when controls are introduced).

Prosocial preferences should be an important determinant of lying behavior. For instance, altruism could restrain the desire to state a selfish black lie that would deteriorate the wellbeing of the receiver of the information. Cappelen et al. (2013) and Biziou-van Pol et al. (2015), using experimental data, show that the aversion to telling a Pareto white lie is stronger among altruistic individuals. ${ }^{10}$ The latter study also shows that altruistic people are more prone to telling an altruistic white lie. ${ }^{11}$

The paper is organized as follows. The next section introduces the experimental design. The results of the experiment are presented in Section 3. Section 4 summarizes the results of the survey on the representative sample of the French population. The last section offers our conclusion.

\footnotetext{
10 The first study used a sample of students in economics, and the second study used an Internet sample of the US general population.

11 Vranceanu and Dubart (2019) found no correlation between lying aversion and inequality aversion.
} 


\section{Experimental design}

The paper and pen experiment was administered in a classroom setting. The sample comprised 178 subjects in their first-year of medical studies in a high-profile medical school in Paris, France, and 163 first-year students in business administration in an equivalently ranked business school in the same geographic area. Students attending regular classes at one of the two institutions were asked twenty minutes before the class break whether they wished to participate in the experiment and had the option to leave the classroom. The sessions took place between October and December 2019. The instructions were very close to those in the EG2012 within-subject design. ${ }^{12}$ The core task is the deception game used in that paper enriched by two additional conditions, to which we add complementary tasks to measure risk tolerance and altruism (see the Appendix for the instructions).

Specifically, this lying game involved a sender and a receiver. The experiment featured two main stages. First, a paper questionnaire was distributed to a group of students in the sender role. The participants were informed that they would be paired within one week with a receiver: "he/she is a student like you, from another higher education institution". We used this general statement to rule out professional socialization or homophyly. The receivers were students in the other school. Similar to EG2012, one in twenty pairs were selected at random to be paid in cash within the three weeks after the senders' decision took place. On average, senders earned 23.8 euros, and receivers obtained 25.7 euros.

The paper questionnaire for the senders contained the main task. The senders were told that at the onset of the experiment, a six-sided die was rolled, and we communicated the outcome to the sender. The sender was presented with five payment possibilities or conditions, each including payment Option $\mathrm{A}\left(s_{A} ; r_{A}\right)$ and payment Option $\mathrm{B}\left(s_{B} ; r_{B}\right)$ in

\footnotetext{
12 Erat and Gneezy (2012) implemented both a between-subject and a within-subject design. Our design combines within-subjects and between-groups comparisons.
} 
which $s_{A}, s_{B}$ were the sender's payoffs, and $r_{A}, r_{B}$ were the receiver's payoffs. The sender was informed that the payment in each condition depended on the choice made by the receiver. If the receiver chose the true outcome of the die roll (unknown to him/her), Option A would be implemented; otherwise, option B would be implemented. For each condition, the sender sent a message that "The outcome of the roll of the die was $i$ ". The receiver had no other information than this statement. From the instructions, he/she knew that there were payoffs associated with each option but had no idea what these payoffs were.

At the end of the experiment, one of the five conditions was selected at random for payment in cash.

Table 1 summarizes the payoffs by condition. ${ }^{13}$ Each subject had to make a choice for each scenario.

\begin{tabular}{|l|l|l|}
\hline Condition & $\begin{array}{l}\text { Option A } \\
\left(s_{A} ; r_{A}\right)\end{array}$ & \multicolumn{1}{|c|}{$\begin{array}{l}\text { Option B } \\
\left(s_{B} ; r_{B}\right)\end{array}$} \\
\hline 1. $T[-1,10]$ & $(20,20)$ & $(19,30)$ \\
\hline 2. $T[1,10]$ & $(20,20)$ & $(21,30)$ \\
\hline 3. $T[10,10]$ & $(20,20)$ & $(30,30)$ \\
\hline 4. $T[1,-5]$ & $(20,20)$ & $(21,15)$ \\
\hline 5. $T[10,-5]$ & $(20,20)$ & $(30,15)$ \\
\hline
\end{tabular}

Table 1: Payoffs by condition (euros)

If option A was chosen, then both players received 20 euros. If option B was chosen, the payoffs were unequal, with gains/losses for the two players as displayed in the table. The within-brackets label of the conditions indicates the change in payoffs for the two players in Option B relative to their payoff in Option A, $T\left[\left(s_{B}-s_{A}\right),\left(r_{B}-r_{A}\right)\right]$. For instance, condition $T[-1,10]$ means that the implementation of Option B provided the receiver with a benefit of 10 euros and a 1 euro loss to the sender compared to the payoffs in Option A.

\footnotetext{
${ }^{13}$ In the instructions, $\mathrm{T}[1,10]$ and $\mathrm{T}[10,10]$ were inverted, exactly as they were presented in Erat and Gneezy (2012). We reverse the labels to follow the intuitive order in which the payoff for the sender is increasing at constant payoff for the receiver.
} 
Sutter (2009) brings into the picture the interesting concept of "sophisticated deception". He studies the sender-receiver game by Gneezy (2005) in which the message space includes only one true message and only one false message. In this context, a dishonest individual who assigns a subjective probability $\pi>0.5$ that the receiver will follow an opposite recommendation to the one given, would tell the truth when he/she actually seeks deception.

Erat and Gneezy (2012) explain that in the more complex message space with six possible statements only one being true, such a sophisticated deception is improbable. Their argument is quite compelling. Let $U^{A}$ be the utility of the sender from Option A, and $U^{B}$ his/her utility from Option B. Option A is implemented if the receiver chooses the true number, and Option $\mathrm{B}$ is implemented if he/she chooses a different number. Denote now by $p$ the probability assigned by the sender to the event that the receiver does not follow his/her recommendation. If the sender tells the truth $($ dice_nb $=2)$, the expected utility is: $E[$ truth $]=(1-p) U_{A}+p U_{B}$. If the sender sends a false message (dice_nb $\neq 2)$, the expected utility is $E[$ lie $]=(1-$ p) $U_{B}+p\left(4 / 5 U_{B}+1 / 5 U_{A}\right)$. Let us assume that the sender prefers Option $B$ to Option $A$, i.e., $U_{B}>U_{A}$. It is easy to check that for $U_{B}>U_{A}, E[$ lie $]>E[$ truth $]$ if $(1-p)>1 / 6$ or $p<5 / 6$. This person would lie if the probability that the other follows his/her recommendation is $(1-p)>1 / 6$, which, as argued by Erat and Gneezy (2012), is a plausible assumption for a majority of senders.

In our experiment, $40 \%$ of the receivers followed the sender's recommendation, which is more than $16.7 \%(\mathrm{p}-\mathrm{val}<0.01)$. If the actual frequency is a good proxy for the expected probability of implemented recommendations, senders should lie about the number on the die if they prefer Option B to Option A, and vice versa.

Stating that the roll of the die was different than the actual number is a lie that the sender delivers with the purpose of making the receiver choose Option B. Given the change 
in payoffs, $T[-1,10]$ corresponds to an altruistic white lie (the sender sacrifices 1 euro for the benefit of the receiver), $T[1,10]$ and $T[10,10]$ correspond to Pareto white lies, and $T[1,-5]$ and $T[10,-5]$ correspond to selfish black lies, i.e., the sender is aware that his/her gain also involves a loss for the receiver.

After making the choice of the number to communicate (sender) or the number to select (receiver), each participant was instructed to move to the second part of the experiment, which was independent of the first part. The instructions for the second part were delivered in a sealed envelope, to avoid any influence of the second part task on the first.

After indicating their age and gender, participants were asked to report their risk tolerance on the scale introduced by Dohmen et al. (2011). The question used is as follows: Thinking of yourself, do you think you are fully prepared to take risks? Subjects could answer from 1 , for "not at all", ..., to 5 , for "very much". Answers were converted into a $(0 ; 1)$ risk tolerance index. ${ }^{14}$

The last task aimed to determine subjects' degree of altruism. They had learned that they received an additional 10 euros, that they could share with a philanthropic organization from a list of 10 charities, all of them well known in France (we exclude organizations from the health sector; see the list in the Instructions). If the pair of subjects of which they were a part was selected for payment, the amount that they indicated would be transferred to one of the associations from the list, selected at random. This 0 to 10 (euro) donation was also converted into a $(0 ; 1)$ altruism index. The total amount transferred to charities was 160 euros. $^{15}$

\footnotetext{
14 The debate on the best method of eliciting risk aversion far is from settled. Different incentivized methods provide uncorrelated measures and are relatively unstable over time (see Crosetto and Filippin, 2016; Beauchamp et al. 2016; Mata et al., 2019). Self-reported measures such as the scale introduced by Dohmen et al. (2011) are less prone to such shortcomings but have limitations specific to unincentivized measures.

15 The donation went to the UNICEF.
} 


\section{Results}

\subsection{General results}

Table 2 reports the frequencies of liars (senders who communicate a number other than the true one) in the overall sample (mixed population) and compares our results with the results in Erat and Gneezy (2012). The latter use undergraduate students taking classes in management as subjects. The similarities in our two sets of results are notable in the domain of Pareto white lies $(T[1,10], T[10,10])$. A notable difference is observed in the domain of selfish lies $(T[1,-5])$, with a lower frequency of liars in our sample. Later we show that this outcome is related to the behavior of medical students.

\begin{tabular}{|l|l|l|}
\hline & EG2012 $(\mathrm{N}=58)$ & This study $(\mathrm{N}=341)$ \\
\hline 1. $T[-1,10]$ & $43 \%$ & $38 \%$ \\
\hline 2. $T[1,10]$ & $66 \%$ & $67 \%$ \\
\hline 3. $T[10,10]$ & $76 \%$ & $77 \%$ \\
\hline 4. $T[1,-5]$ & $52 \%$ & $38 \%$ \\
\hline 5. $T[10,-5]$ & n.a. & $62 \%$ \\
\hline
\end{tabular}

Table 2: A comparison with Erat and Gneezy (2012).

Even if the lie benefits both subjects, approximately $1 / 4$ of the senders never lie, as if they follow some categorical imperative, tantamount to experiencing a very large cost from lying.

The within subject design allows for an additional check that incentives have an impact on the decision to lie. We present contingency tables separately for Pareto white lies (Table 3) and selfish lies (4).

In the Pareto white lie situation, 62 of the 113 subjects who tell the truth in $T[1,10]$ switch to lying in $T[10,10]$ when their benefit from lying increases. A much smaller number (28 subjects) have the counterintutive reaction of telling the truth in $T[10,10]$ yet switching to lying in $\mathrm{T}[1,10] ;\left(\chi^{2}=45.5, p<0.01\right)$. They could belong to a special category of moral subjects who lie if there is a clear benefit to the other participant, but not when they obtain 
the same benefit.

\begin{tabular}{|l|l|l|l|l|}
\hline & & \multicolumn{2}{|l|}{$T[10,10]$} & \\
\hline & & Truth & Lie & Total \\
\hline$T[1,10]$ & Truth & 51 & 62 & 113 \\
\hline & Lie & 28 & 199 & 227 \\
\hline & Total & 79 & 261 & 340 \\
\hline
\end{tabular}

Table 3: Contingency table: Pareto white lies

In the selfish lie situation, 99 out of 212 subjects switch from telling the truth to lying for a higher benefit (at the same cost to the receiver); only 16 subjects lie in $T[1,-5]$ and tell the truth in $T[10,-5]$ when lying brings them a larger benefit $\left(\chi^{2}=57.0, p<0.01\right)$.

\begin{tabular}{|l|l|l|l|l|}
\hline & & \multicolumn{2}{|l|}{$T[10,-5]$} & \\
\hline & & Truth & Lie & Total \\
\hline$T[1,-5]$ & Truth & 113 & 99 & 212 \\
\hline & Lie & 16 & 113 & 129 \\
\hline & Total & 129 & 212 & 341 \\
\hline
\end{tabular}

Table 4: Contingency table: Selfish lies

We can now turn our attention to the key research question of the differences between the two professional profiles. We first analyze the differences in personal characteristics and then study the differences in lying behavior.

\subsection{Business vs. medical students}

Table 5 presents the key personal characteristics of the two populations of medicine and business students.

\begin{tabular}{|l|l|l|l|l|}
\hline & Gender $(\mathrm{Fe}=1)$ & Age & Altruism $(0-1)$ & Risk tol. $(0-1)$ \\
\hline Medicine students $(\mathrm{N}=178)$ & $0.70(0.04)$ & $19.78(0.23)$ & $0.84(0.02)$ & $0.53(0.02)$ \\
\hline Business students $(\mathrm{N}=162)$ & $0.41(0.04)$ & $18.43(0.11)$ & $0.79(0.02)$ & $0.64(0.02)$ \\
\hline Total $(\mathrm{N}=341)$ & $0.56(0.03)$ & $19.13(0.13)$ & $0.81(0.02)$ & $0.58(0.02)$ \\
\hline
\end{tabular}

Table 5: Personal characteristics by profile (s.e.)

In general, in France medical studies attract a larger proportion of women than do business studies; in the two higher education institutions, women represent $68 \%$ and $51 \%$ of the 
total population, respectively, which is reflected in the different proportions of female subjects across the two groups $(p<0.01)$. Additionally, the medical students in our sample are one year older than the business students, on average. While the mean measure of altruism is slightly larger in the sample of medical students than in the sample of business students (0.84 vs. 0.79$)$, this difference is not statistically significant $(p=0.13) .{ }^{16}$

On average, business students present a higher risk tolerance $(p<0.01)$. This result might be qualified because the sample of business students includes a smaller percentage of women (who, on average, have a lower risk tolerance; see Table 11 in Appendix I). A regression model (unreported) confirms that this difference in self-reported risk tolerance between the two professions persists after controlling for the gender of the respondent.

Table 6 presents the proportions of senders who lie, by type of lie (the five conditions) and sender profile.

\begin{tabular}{|l|l|l|l|}
\hline & \multicolumn{1}{|c|}{$\begin{array}{c}\text { Medicine } \\
(\mathrm{N}=178)\end{array}$} & $\begin{array}{c}\text { Business } \\
(\mathrm{N}=163)\end{array}$ & $\begin{array}{l}(\mathrm{p} \text {-val }) \\
\text { diff. between } \mathrm{m} / \mathrm{b}\end{array}$ \\
\hline 1. $T[-1,10]$ & $36 \%$ & $39 \%$ & $(0.53)$ \\
\hline 2. $T[1,10]$ & $67 \%$ & $66 \%$ & $(0.79)$ \\
\hline 3. $T[10,10]$ & $79 \%$ & $74 \%$ & $(0.28)$ \\
\hline 4. $T[1,-5]$ & $27 \%$ & $50 \%$ & $(0.00)$ \\
\hline 5. $T[10,-5]$ & $53 \%$ & $72 \%$ & $(0.00)$ \\
\hline
\end{tabular}

Table 6: Proportion of senders who lie by type of lie and professional profile

Comparing the two profiles, we observe substantial similarities in the domain of white lies and substantial differences in the domain of selfish lies, with business students more willing to tell a selfish lie. We can confirm that only the frequencies reported for business students are now very close to those in the data reported by Erat and Gneezy (2012).

A substantial proportion, $21 \%$ of the medical students and $26 \%$ of the business students, refuse to state a Pareto white lie that increases the payoffs of both participants by as much

\footnotetext{
${ }^{16}$ If no indication is provided, in this text, p-values correspond to two-sided t-tests.
} 
as 10 euros.

Students of both profiles respond to incentives as documented by Gneezy (2005) and Erat and Gneezy (2012):

- At a constant gain for the receiver, the sender lies more often if his/her benefit is large (in Figure 2, the frequency of lying increases from left to right on a given horizontal line).

- At a constant gain for the sender, the sender lies less often when the receiver is losing something compared to when the receiver is gaining something (in Figure 2, the frequency decreases from top to bottom on a given vertical line). However, for business students, no change is observed for the large payoff.

We can use a regression model to verify whether this pattern holds when controlling for personal characteristics.

Table 7 displays the output of OLS regressions where the dependent variable is a dummy "Lie", which takes the value of 1 if the subject has told a lie in a given condition (i.e., in our case, reported a number different from 2). Individual data are stacked by condition. There is a dummy variable "Med", taking the value of 1 (0) for medical (business) students, and there is a dummy for each of the five conditions, $D_{-} T[$, ], taking the value of 1 for that condition, and zero otherwise. The altruistic lie condition $(T[-1,10])$ serves as the benchmark. Other covariates are: gender $($ female $=1$ ), age, self-reported risk tolerance, and the elicited altruism measure. Observations are not independent since each subject provides five distinct answers. To correct for this bias, errors are clustered by subject. ${ }^{17}$

Result 1. The results of the regressions corroborate the existence of the incentive effect:

\footnotetext{
${ }^{17}$ In OLS regressions, coefficients can be interpreted directly as changes in the probability of stating a lie. Unreported probit models provide very similar results.
} 


\begin{tabular}{|l|l|l|l|}
\hline & Model 1 & Model 2 & Model 3 \\
\hline$D \_T[1,10]$ & $0.268^{* * *}(0.05)$ & $0.273^{* * *}(0.05)$ & $0.281^{* * *}(0.05)$ \\
\hline$D \_T[10,10]$ & $0.350^{* * *}(0.05)$ & $0.350^{* * *}(0.05)$ & $0.358^{* * *}(0.05)$ \\
\hline$D \_T[1,-5]$ & $0.104^{* * *}(0.05)$ & $0.100^{*}(0.05)$ & $0.101^{*}(0.05)$ \\
\hline$D \_T[10,-5]$ & $0.331^{* * *}(0.05)$ & $0.331^{* * *}(0.05)$ & $0.333^{* * *}(0.05)$ \\
\hline Med stud. $(=1)$ & $-0.033(0.05)$ & $-0.028(0.06)$ & $-0.007(0.06)$ \\
\hline Med $\times D \_T[1,10]$ & $0.047(0.06)$ & $0.039(0.06)$ & $0.031(0.06)$ \\
\hline Med $\times D \_T[10,10]$ & $0.083(0.07)$ & $0.084(0.07)$ & $0.075(0.07)$ \\
\hline Med $\times D \_T[1,-5]$ & $-0.194^{* * *}(0.07)$ & $-0.198^{* * *}(0.07)$ & $-0.199^{* * *}(0.07)$ \\
\hline Med $\times D \_T[10,-5]$ & $-0.163^{* *}(0.07)$ & $-0.175^{* *}(0.07)$ & $-0.177^{* *}(0.07)$ \\
\hline Female $(=1)$ & & $0.028(0.03)$ & $0.040(0.03)$ \\
\hline Age & & $-0.002(0.01)$ & $-0.002(0.01)$ \\
\hline Risk tolerance & & & $0.154^{*}(0.08)$ \\
\hline Altruism & & & $-0.071(0.05)$ \\
\hline Constant & $0.393^{* * *}(0.04)$ & $0.416^{* * *}(0.15)$ & $0.370^{* *}(0.15)$ \\
\hline R2 & 0.12 & 0.12 & 0.13 \\
\hline N & 1704 & 1664 & 1659 \\
\hline Legend: * significant at $10 \% ;{ }^{* *}$ significant at 5\%; ${ }^{* * *}$ significant at $1 \%$. Std. err. within parentheses. \\
\hline
\end{tabular}

Table 7: The "general" lying equation, pooled data

as shown by the coefficients of the condition dummies, individuals of both profiles lie more if their benefit is increasing at a constant payoff for the receiver and lie less if the benefit to the receiver deteriorates at a small constant gain for themselves (but not for the large gain). Note that Model 1 is a plain replica of the probabilities displayed in the descriptive statistics in Table 6 (the constant term is the frequency of business students telling altruistic lies). Including personal characteristics does not greatly alter the elementary proportions.

Result 2. The interaction terms for the Pareto white lies are not statistically significant, revealing no difference between the two types of students with respect to these prosocial lies.

Result 3. There is a significant medicine study effect in the domain of selfish lies. Even when controlling for the degree of altruism and risk tolerance, depending on the condition, medical students have an $18 \%$ to $20 \%$ lower probability of telling a selfish lie than business students. This result is consistent with findings by Lundquist et al. (2009), Lewis et al. (2012) and López-Pérez and Spiegelman (2019), who show that students in business and economics tend to engage more easily in selfish lying than subjects in other fields. 
We can also perform the same analysis separately for medicine and business students; the interaction terms are no longer needed. Table 8 presents the results of OLS regressions, with errors clustered by subject.

\begin{tabular}{|l|l|l|l|l|}
\hline & \multicolumn{2}{|l|}{ Medicine students } & \multicolumn{2}{l|}{ Business students } \\
\hline & Model 1 & Model 2 & Model 1 & Model 2 \\
\hline$D \_T[1,10]$ & $0.312^{* * *}(0.04)$ & $0.312^{* * *}(0.04)$ & $0.273^{* * *}(0.05)$ & $0.281^{* * *}(0.05)$ \\
\hline$D \_T[10,10]$ & $0.434^{* * *}(0.05)$ & $0.434^{* * *}(0.05)$ & $0.350^{* * *}(0.05)$ & $0.358^{* * *}(0.05)$ \\
\hline$D \_T[1,-5]$ & $-0.098^{*}(0.05)$ & $-0.098^{*}(0.05)$ & $0.100^{*}(0.05)$ & $0.101^{*}(0.05)$ \\
\hline$D \_T[10,-5]$ & $0.156^{* * *}(0.05)$ & $0.156^{* * *}(0.05)$ & $0.331^{* * *}(0.05)$ & $0.333^{* * *}(0.05)$ \\
\hline Female $(=1)$ & $0.006(0.05)$ & $0.013(0.05)$ & $0.048(0.04)$ & $0.065(0.05)$ \\
\hline Age & $-0.001(0.01)$ & $-0.002(0.01)$ & $-0.011(0.01)$ & $-0.010(0.02)$ \\
\hline Risk toler. & - & $0.146(0.10)$ & - & $0.161(0.13)$ \\
\hline Altruism & - & $-0.092(0.07)$ & - & $-0.059(0.08)$ \\
\hline Constant & $0.382^{* *}(0.17)$ & $0.390^{* * *}(0.17)$ & $0.572^{* *}(0.28)$ & $0.491(0.37)$ \\
\hline N & 865 & 865 & 799 & 794 \\
\hline R2 & 0.153 & 0.160 & 0.082 & 0.09 \\
\hline Legend: * significant at 10\%; ** significant at 5\%; *** significant at 1\%. Std. err. within parentheses. \\
\hline
\end{tabular}

Table 8: The "general" lying equation

The results confirm the presence of the incentive effect. Furthermore, medical students appear to react much more strongly to the deterioration of the well-being of the other by reducing their lying: at a benefit of 1 euros for themselves, with payoff change going from 10 euros to -5 euros for the receiver, the average sender who is a medicine student reduces his/her frequency of lying by $31.2 \%-(-9.8 \%)=41 \%$. Moreover, at a payoff of 10 euros for themselves, going from 10 euros to -5 euros for the receiver, their frequency of lying falls by $43.4 \%-15.6 \%=27.8 \%$. On the other hand, for the business students, the frequency of lying in the same situations falls by only $27.3 \%-10 \%=17.3 \%$ and only $35 \%-33 \%=2 \%$.

Table 9 provides estimates of "condition-specific" lying equations, one for each of the five scenarios (the subject provides only one answer, for that specific condition). For each condition, the dependent variable is a dummy variable taking the value of 1 if the subject has told a lie. The other covariates are similar to those used in the previous regressions. We also include a gender $\times$ profession interaction term. 
Table 9 reports the output of OLS regressions for each type of lie; ${ }^{18}$

\begin{tabular}{|c|c|c|c|c|c|}
\hline & $T[-1,10]$ & $T[1,10]$ & $T[10,10]$ & $T[1,-5]$ & $T[10,-5]$ \\
\hline Age & $-0.004(0.01)$ & $0.010^{* * *}(0.00)$ & $-0.013^{* *}(0.00)$ & $-0.006^{*}(0.00)$ & $-0.003(0.00)$ \\
\hline Altruism & $-0.003(0.09)$ & $-0.015(0.09)$ & $-0.019(0.04)$ & $-0.141^{*}(0.08)$ & $-0.183^{*}(0.07)$ \\
\hline Risk tol. & $0.209(0.14)$ & $0.232^{* * *}(0.04)$ & $0.096(0.07)$ & $0.131(0.12)$ & $0.118(0.16)$ \\
\hline Female $(=1)$ & $-0.054(0.12)$ & $-0.068^{* * *}(0.01)$ & $0.119(0.07)$ & $0.107(0.05)$ & $0.117(0.10)$ \\
\hline Med. stud. $(=1)$ & $0.165^{*}(0.06)$ & $0.063(0.03)$ & $0.154^{*}(0.07)$ & $-0.217^{* * *}(0.03)$ & $-0.182^{* *}(0.06)$ \\
\hline Female $\times$ Med & $-0.026(0.04)$ & $0.021(0.02)$ & $0.126^{*}(0.05)$ & $-0.113^{* *}(0.03)$ & $-0.096(0.05)$ \\
\hline Constant & $0.299^{*}(0.11)$ & $0.374^{* *}(0.09)$ & $0.877^{* * *}(0.05)$ & $0.582(0.16)$ & $0.797^{* *}(0.20)$ \\
\hline $\mathrm{N}$ & 332 & 331 & 332 & 332 & 332 \\
\hline $\mathrm{R} 2$ & 0.03 & 0.02 & 0.02 & 0.07 & 0.06 \\
\hline
\end{tabular}

Table 9: "Condition-specific" lying equations

These regression models corroborate the previous results and provide new information.

Result 4. The behavior of the students regarding the altruistic white lies (which was the benchmark in the former regressions) follows the same pattern as the behavior regarding the Pareto white lies. More precisely, there is no profile effect in the domains of altruistic white lies or Pareto white lies (there is a weak positive effect affecting medical students when their benefit is large).

Result 5. As expected, altruism has a (weak) limiting effect on selfish lies (which deteriorate the income of the receiver). In our data, altruism is not related to the decision to tell a Pareto white lie or an altruistic lie; this result contrasts with the findings of Cappelen et al. (2013) and Capraro et al. (2015) who find that the aversion to telling a Pareto white lie is stronger among altruistic individuals.

Result 6. These results point out gender effects. Capraro (2018) performed a metaanalysis on 65 sender-receiver deception games and found that men are significantly more likely than women to tell both black and altruistic white lies; the results were inconclusive in the case of Pareto white lies. ${ }^{19}$ In our data, the frequencies of men and women telling selfish

\footnotetext{
18 Probit estimates reveal similar results.

19 As examples of sender-receiver lab experiments showing that men tend to resort to selfish lies more often
} 
lies are quite similar (see Appendix table 12). However, in the $T[1,-5]$ selfish lie model, the coefficient of the interaction term between gender (female) and field of study (medicine) is negative, showing that women studying medicine have a higher reluctance to tell selfish lies. This result is in line with López-Pérez and Spiegelman (2019), who find that women studying business and economics engage more often in selfish lies than do women in other fields.

\section{Beliefs and actual behavior: survey data}

These lab experiments allowed us to directly observe students' lying behavior and revealed significant differences. The sample included only first-year students who had not been exposed to intensive specific training. Thus, the observed lying behavior can be related to the motives that prompted them to choose their future profession in the first place. Unfortunately, our experiment does not allow us to say much about what these motives may be.

To complement the analysis, we asked the survey institute Opinion Way to provide a report on how the general public of France perceives the lying behavior of the two groups of students. To keep the complexity and number of questions relatively low, in the survey, we focused on the polar cases of selfish black lies and altruistic white lies (Pareto white lies were omitted). Four specific questions were included in the omnibus weekly survey. Data collection was carried out on July 2nd, 2020. The sample of 1056 respondents is representative of the French population of 18 years or more. ${ }^{20}$ In total, $2 \%$ of polled persons did not answer our questions, which yields 1035 valid answers. Respondents received a fixed reward or could opt for a gift to the charity of their choice.

The questions are as follows:

than women do, see: Gill et al., 2013; Conrads et al., 2013; Dreber and Johannesson, 2008; Erat and Gneezy, 2012; Kleinknecht, 2019.

${ }^{20}$ Segmentation criteria are age, gender, socioprofessional category, type of residency and region. The survey is administered by computer-assisted web interviews. 
"You consider an exchange of information between a person who sends a message and a person who receives it. In this exchange, the sender of the message can either tell the truth, i.e., convey exact information, or lie, i.e., convey false information. Academic research has defined two types of important lies: a "black lie", which entails positive consequences for the liar and negative consequences for the receiver of the misleading message; these lies are beneficial to the liar at the expense of the receiver; and a "white lie", which brings a benefit to the person who receives it, and is costly to the person who tells it.

Please indicate whether you agree or disagree with the following four statements:

S1. An undergraduate student in medicine is more prone to tell black lies than an undergraduate student in business administration

S2. An undergraduate student in medicine is more prone to tell white lies than an undergraduate student in business administration

S3. In general, the use of black lies is more frequent in the business world than in the the medical world

S4. In general, the use of white lies is more frequent in the business world than in the medical world

The answers were recorded on a seven-item scale, from 1 (full disagreement) to 7 (full agreement), 4 being the neutral case.

The first two items (S1 and S2) are directly related to the experiment. They aim to gauge how the general population perceives the lying behavior of the two groups of students.

Items 3 and 4 aim to capture the general opinion on deception within the business profession and the medical profession.

In the implementation of the survey, items 1 and 2 were alternated, as were items 3 and 4. 
Table 10 presents the synthesis of the results that consolidates all affirmative ( 5 to 7 ), and all negative (1 to 3 ) answers (the seven-category distribution is presented in Appendix Table 13). The last column presents the output of a z-test for one proportion of the nonneutral observations.

\begin{tabular}{|l|l|l|l|l|}
\hline & At least slight disagreement & Neutral & At least slight agreement & \\
\hline S1 & $36.3 \%$ & $53.9 \%$ & $9.8 \%$ & $\mathrm{p}<0.001$ \\
\hline S2 & $23.0 \%$ & $54.4 \%$ & $22.7 \%$ & $\mathrm{p}=0.890$ \\
\hline S3 & $15.2 \%$ & $41.0 \%$ & $43.8 \%$ & $\mathrm{p}<0.001$ \\
\hline S4 & $36.4 \%$ & $44.2 \%$ & $19.4 \%$ & $\mathrm{p}<0.001$ \\
\hline
\end{tabular}

Table 10: Opinions on lying differences

In the experiment, there was no difference between the two groups of students with respect to prosocial lies. In the survey, a majority of the respondents (53.9\%) chose the neutral answer, and equal proportions of respondents agree and disagree with the statement that students in medicine are more prone than students in business to tell white lies.

However, only a small number of respondents (9.8\%) agreed that medical students are more tempted to tell selfish lies, compared to $36.3 \%$ who disagreed. This skewed distribution of the opinions is in line with the results of the experiment showing that, on average, business students tell selfish lies more often than medical students.

With respect to their opinion on the use of the two types of lies in the two professions, the respondents consider that selfish lies are more frequent in the business world than in the medical sector ( $43.8 \%$ agree while only $15.2 \%$ disagree); the opinions reverse for the case of white lies (36.4\% disagree while 19.4\% agree). According to these "folk beliefs", the business profession in general provides a more fertile ground for selfish lies; on the other hand, the medical profession provides a more supportive environment for white lies.

Schneider et al. (2020) have shown that immoral work attracts those workers least concerned with acting morally, which in turn can deteriorate the moral standards of some 
professions. This could be a possible explanation for why students of a given lying pattern self-select into one of the two professions: if people in general believe that, for example, in the business world selfish lies are the norm, those with a taste for selfish lies may be likely to choose that profession. Furthermore, if people with a taste for selfish lies self-select into the business profession, over time, this profession will comprise more people of this type than the medical profession, which validates the beliefs of the general public. This set of beliefs and actual profession choices can be defined as self-fulfilling prophecies (Nash Bayesian equilibrium).

\section{Conclusion}

In the last fifteen years, the literature in experimental economics on lies and deception has expanded at a steady pace. This paper analyzes the differences in lying behavior between two groups of subjects exposed to different professional norms, expectations and stereotypes, namely, business and medical students.

In the world of business, many professionals find it legitimate to exploit any trading opportunity, including a would-be informational advantage. Economists like to believe that strong competition among firms rules out systematic rent extraction but are relatively silent about the ethical consequences of trading with a player who has market power. However, lying in negotiations, with sellers exaggerating costs and buyers understating their willingness to pay, is a common practice. For many trading people, a "good" deal is one in which one party obtains most of the surplus from trade at the expense of the other and sometimes in sheer disregard of the interest of the other. In contrast, centuries of medical practice throughout history reveal that physicians seldom exploit their informational advantage and act in the interest of the patients even at personal cost. Such behavior is grounded in the professional norms inspired by the Hippocratic oath, according to which the interest 
of the patient should always prevail. In turn, these professional norms should attract the most pro-social persons to this field. Selfish lies are not tolerated, while some white lies, such as prescribing a placebo or hiding very bad news, could be common. Of course, these stereotypes have their own exceptions in both worlds. In the health sector in particular, conflicts of interest and the hiding of medical errors have sometimes been revealed.

The experiment presented in this paper allowed us to directly observe the lying behavior of the respective groups. We used the classic sender-receiver deception game by Erat and Gneezy (2012) to determine and assess the importance of those behavioral differences. The complementary giving-to-charity task did not reveal any substantial difference in altruism between the two groups; however, business students present a higher risk tolerance.

Turning to the strategic communication issue, it turns out that students of both profiles respond to incentives, as documented in Gneezy (2005) and Erat and Gneezy (2012). However, while many students lie, a nonnegligible share of both medicine and business students refuse to tell even a Pareto white lie, which would deliver significant gains to both parties.

The propensity to tell white lies was similar between the two groups. On the other hand, medical students appear to be significantly more reluctant than business students to tell selfish lies, a result that holds when controlling for altruism and risk aversion. Medical students exhibit a higher concern that their partner will be harmed by misleading communication.

The fact that both types of students behave in the same way in terms of telling white lies but differ with respect to selfish lies is troubling. If moral people just dislike lying, regardless of the consequences for others, then there should be no differences between the two groups for both types of lies. The results point to some differences in student's perceptions of how harmful or legitimate the use of selfish lies can be, with business students telling selfish lies more easily than medical students. 
A representative survey of the French population, conducted in July 2020 by Opinion Way for the purpose of this paper, revealed that the general public of France expects selfish lies to be more frequent in the business sector than in the medical sector, the opposite holding for white lies. The general public tends to believe that the frequency of selfish liars is higher among business students than among medical students. These results match the behavior observed in the experiment, and might suggest one among many possible explanations of why young people self-select for a given profession. If telling selfish lies is the norm in the business world but not in medicine, students with a taste for selfish lies would enroll in business studies, and those who are more averse to selfish lies would enroll in medicine.

It is very difficult to draw any moral criticism or lesson from the evidence provided in this paper since each profession has its own communication norms. However, from a methodological point of view, it is important to keep in mind that results obtained from samples of students in business and economics, which are the main groups of the public considered in economics lab experiments, might not be representative of the deception behavior of the general population. To strengthen the external validity of these studies, it might be useful to perform replication studies of the main deception experiments on different types of subjects.

Acknowledgement 1 This research was funded by academic grants provided by the Direction de la Recherche, International, Valorization et Ecoles doctorales (DRIVE) of the University of Paris Descartes and the LABEX MME DII of the University of Cergy Pontoise. It benefited from the agreement of the Ethical Committee of University of Paris Descartes on April 18, 2019. The authors are grateful to Delphine Dubart, at the ESSEC Experimental Lab, for her technical assistance, as well to Thierry Aimar, Nathalie Charnaux, Cécile Badoual, Jeanne Bregier, Philippe Henry, Fabrice Jollant, Marie-France Mamzer, Sophie $\mathrm{Ng}$ Wing Tin, and Jean Ralph Zahar for their support during the different implementation stages of the experiment. They would like to thank Angela Sutan and Eli Spiegelman for their suggestions and remarks on an early version of the paper.

\section{References}

Abeler, Johannes, Anke Becker, and Armin Falk, 2014. Representative evidence on lying costs, Journal of Public Economics, 113: 96-104. 
Abeler, Johannes, Daniele Nosenzo, and Collin Raymond, 2019. Preferences for truthtelling. Econometrica, 87, 4: 1115-1153.

Ahlert, Marlies, Stefan Felder and Bodo Vogt, 2012. Which patients do I treat? An experimental study with economists and physicians, Health Economics Review, 2, 1.

Aquino, Karl, and Thomas E. Becker, 2005. Lying in negotiations: How individual and situational factors influence the use of neutralization strategies. Journal of Organizational Behavior, 26, 6: 661-679.

Arrow, Kenneth J., 1963. Uncertainty and the welfare economics of medical care. American Economic Review, 53: 941-973.

Balsa, Ana I., and Thomas G. McGuire, 2003. Prejudice, clinical uncertainty and stereotyping as sources of health disparities, Journal of Health Economics 22, 1: 89116 .

Barcelo, Helene and Capraro, Valerio, 2019. On the heterogeneity of people's (dis)honest behavior along two dimensions: Cost of lying and cost of acquiring information, Available at SSRN: https://ssrn.com/abstract=3094305

Biziou-van-Pol, Laura, Jana Haenen, Arianna Novaro, Andrés Occhipinti Liberman, 2015. Does telling white lies signal pro-social preferences? Judgment and Decision Making, 10: 538-548.

Beauchamp, Tom L., and James F. Childress, 1994. Principles of Biomedical Ethics. 4th edition, New York, Oxford: Oxford University Press.

Beauchamp, Jonathan P., David Cesarini, and Magnus Johannesson, 2017. The psychometric and empirical properties of measures of risk preferences. Journal of Risk and Uncertainty 54, 3: 203-237.

Brosig-Koch, Jeannette, Heike Hennig-Schmidt, Nadja Kairies-Schwarz, and Daniel Wiesen, 2017. The effects of introducing mixed payment systems for physicians: Experimental evidence. Health Economics, 26, 2: 243-262.

Brock, J. Michelle, Andreas Lange, and Kenneth L. Leonard, 2016. Generosity and prosocial behavior in healthcare provision evidence from the laboratory and field, Journal of Human Resources 51, 1: 133-162.

Cappelen, Alexander W., Erik Ø. Sørensen, and Bertil Tungodden, 2013. When do we lie?. Journal of Economic Behavior and Organization, 93: 258-265.

Capraro, Valerio, 2018. Gender differences in lying in sender-receiver games: A metaanalysis. Judgment and Decision Making, 13, 4: 345-355.

Chelliah, John, and Yogita Swamy, 2018. Deception and lies in business strategy. Journal of Business Strategy, 39, 6: 36-42.

Charness, G. and M. Dufwenberg (2006). Promises and partnership, Econometrica, 74, 1579-1601.

Cox, James C., Ellen Green, and Heike Hennig-Schmidt, 2016. Experimental and behavioral economics of healthcare. Journal of Economic Behavior and Organization, 131, A1-A4. https://doi.org/10.1016/j.jebo.2016.10.011. 
Conrads, Julian, Bernd Irlenbusch, Rainer M. Rilke, and Gari Walmowitz, 2013. Lying and team incentives, Journal of Economic Psychology, 34: 1-7.

Crawford, Vincent P., and Joel Sobel, 1982. Strategic information transmission, Econometrica, 50, 6: 1431-1451.

Crosetto, Paolo, and Antonio Filippin. 2016, A theoretical and experimental appraisal of four risk elicitation methods. Experimental Economics 19, 3: 613-641.

Docan-Morgan, Tony, 2019. (Ed.), The Palgrave Handbook of Deceptive Communication, Palgrave Macmilan.

Dohmen, Thomas, Armin Falk, David Huffman, Uwe Sunde, Jürgen Schupp and Gert G. Wagner, 2011. Individual risk attitudes: Measurement, determinants, and behavioral consequences. Journal of the European Economic Association, 9, 3: 522-550.

Dufwenberg, M. and M. A. Dufwenberg 2018. Lies in disguise - A theoretical analysis of cheating, Journal of Economic Theory, 175, 248 - 264

Dreber, A. and Johannesson, M., 2008. Gender differences in deception, Economics Letters, 99, 1: 197-199.

Erat, Sanjiv, and Uri Gneezy, 2012. White lies. Management Science 58, 4: 723-733.

Ellingsen, Tore, and Magnus Johannesson. 2008. Pride and prejudice: The human side of incentive theory. American Economic Review 98.3: 990-1008.

Ellis, Randall P., and Thomas G. McGuire, 1986. Provider behavior under prospective reimbursement: Cost sharing and supply, Journal of Health Economics 5, 2: 129-151.

Fischbacher, Urs, and Franziska Föllmi-Heusi, 2013. Lies in disguise-an experimental study on cheating, Journal of the European Economic Association, 11, 3: 525-547.

Fehr, Ernst, and Klaus M. Schmidt, 1999. A theory of fairness, competition, and cooperation. Quarterly Journal of Economics 114, 3: 817-868.

Galizzi, Matteo M., and Daniel Wiesen, 2018. Behavioral experiments in health economics, Oxford Research Encyclopedia; Economics and Finance, Online at: DOI: 10.1093/acrefore/9780190625979.013.244

Gerlach, Philipp, Kinneret Teodorescu, and Ralph Hertwig, 2019. The truth about lies: A meta-analysis on dishonest behavior. Psychological Bulletin 145: 1.

Gill, David, Prowse, Victoria and Vlassopoumos, Michael, 2013. Cheating in the workplace: An experimental study of the impact of bonuses and productivity, Journal of Economic Behavior and Organization, 96, 1: 120-134.

Gneezy, Uri, 2005. Deception: The role of consequences. American Economic Review 95, 1: 384-394.

Gneezy, Uri, Agne Kajackaite, and Joel Sobel, 2018. Lying aversion and the size of the lie. American Economic Review 108, 2: 419-53.

Gneezy, U., Saccardo, S., Serra-Garcia, M. and van Veldhuizen, R., 2020. Bribing the self. Games and Economic Behavior, 120: 311-324. 
Godager, Geir, and Daniel Wiesen, 2013. Profit or patients' health benefit? Exploring the heterogeneity in physician altruism. Journal of Health Economics, 32, 6: 1105-1116.

Hayek, Friedrich, 1945. The use of knowledge in society, American Economic Review, 35, 4: 519-530.

Henning-Schmidt, Heike and Jürges, Hendrik and Wiesen, Daniel, 2018. Dishonesty in healthcare practice: A behavioral experiment on upcoding in neonatology. Available at $S S R N$ : ssrn.com/abstract=3152298 or http://dx.doi.org/10.2139/ssrn.3152298.

Hennig-Schmidt, Heike, Reinhard Selten, and Daniel Wiesen, 2011. How payment systems affect physicians' provision behaviour-an experimental investigation. Journal of Health Economics 30, 4: 637-646.

Hoerni, Bernard, 2003. L'éthique médicale. Principales évolutions au fil des siècles, Histoire des Science Médicale, 37, 3.

Holland, J. L., 1985. Making Vocational Choices: A Theory of Careers. Englewood Cliffs, NJ: Prentice-Hall.

Iezzoni, L. I., Rao, S. R., DesRoches, C. M., Vogeli, C., \& Campbell, E. G., 2012. Survey shows that at least some physicians are not always open or honest with patients. Health Affairs, 31 (2), 383-391.

Jacobsen, Catrine, Toke Reinholt Fosgaard, and David Pascual-Ezama, 2018. Why do we lie? A practical guide to the dishonesty literature. Journal of Economic Surveys, 32, 2: 357-387.

Kesternich, Iris, Heiner Schumacher, and Joachim Winter, 2015, Professional norms and physician behavior: homo oeconomicus or homo hippocraticus?, Journal of Public Economics, 131: 1-11.

Khalmetski, Kiryl, and Dirk Sliwka, 2019. Disguising lies-Image concerns and partial lying in cheating games. American Economic Journal: Microeconomics 11.4 : 79-110.

King, Marissa, and Peter S. Bearman, 2017. Gifts and influence: Conflict of interest policies and prescribing of psychotropic medications in the United States, Social Science \& Medicine 172 : 153-162.

Kleinknecht, Janina, 2019. A man of his word? An experiment on gender differences in promise keeping, Journal of Economic Behavior and Organization, 168: 251-268

Knight Frank H, 1923. The ethics of competition, Quarterly Journal of Economics, 37, 4: $579-624$.

Jacobsen, C., Fosgaard, T. R., \& Pascual-Ezama, D., 2018. Why do we lie? A practical guide to the dishonesty literature. Journal of Economic Surveys, 32 (2): 357-387.

Li, Jing, William H. Dow, and Shachar Kariv, 2017. Social preferences of future physicians. Proceedings of the National Academy of Sciences 114, 48: E10291-E10300.

Levine, Emma E., and Maurice E. Schweitzer, 2014. Are liars ethical? On the tension between benevolence and honesty, Journal of Experimental Social Psychology 53: 107117. 
Levine, E., Hart, J., Moore, K., Rubin, E., Yadav, K., \& Halpern, S. 2018. The surprising costs of silence: Asymmetric preferences for prosocial lies of commission and omission. Journal of personality and social psychology, 114 (1), 29.

Lewis, A., Bardis, A., Flint, C., Mason, C., Smith, N., Tickle, C., \& Zinser, J. 2012. Drawing the line somewhere: An experimental study of moral compromise. Journal of Economic Psychology, 33 (4), 718-725.

López-Pérez Raul and Eli Spiegelman, 2019. Do economists lie more?, In: A. Bucciol and N. Montinari (Eds.), Dishonesty in Behavioral Economics: 143-162.

Lundquist, T., Ellingsen, T., Gribbe, E., and Johannesson, M., 2009. The aversion to lying. Journal of Economic Behavior \&6 Organization, 70 (1-2): 81-92.

Lupoli, Matthew J., Lily Jampol, and Christopher Oveis, 2017. Lying because we care: Compassion increases prosocial lying. Journal of Experimental Psychology: General 146, 7: 1026.

Mata, Rui, Renato Frey, David Richter, Jürgen Schupp, and Ralph Hertwig, 2018. Risk preference: A view from psychology. Journal of Economic Perspectives, 32, 2: 155-72.

Mazar, Nina, On Amir, and Dan Ariely, 2008. The dishonesty of honest people: A theory of self-concept maintenance. Journal of Marketing Research, 45, 6: 633-644.

Martinsson, Peter and Emil Persson, 2019. Physician behavior and conditional altruism: the effects of payment system and uncertain health benefit, Theory and Decision, 87, 3: $365-387$.

McCabe, Donald L., and Linda Klebe Trevino, 1995. Cheating among business students: A challenge for business leaders and educators. Journal of Management Education 19, 2: 205-218.

McCabe, Donald L., Janet M. Dukerich, and Jane E. Dutton, 1994. The effects of professional education on values and the resolution of ethical dilemmas: Business school vs. law school students. Journal of Business Ethics 13, 9: 693-700.

Racko, Girts, Karoline Strauss and Brendan Burchell, 2017. Economics education and value change: The role of program-normative homogeneity and peer influence, Academy of Management Learning and Education, 16, 3.

Rosenbaum, Stephen Mark, Stephan Billinger, and Nils Stieglitz, 2014. Let's be honest: A review of experimental evidence of honesty and truth-telling, Journal of Economic Psychology 45: 181-196.

Sah, Sunita, and Adriane Fugh-Berman, 2013. Physicians under the influence: social psychology and industry marketing strategies, Journal of Law, Medicine $\mathcal{E}$ Ethics 41, 3: $665-672$.

Schneider, Florian, Fanny Brun, and Roberto A. Weber, 2020. Sorting and wage premiums in immoral work University of Zurich, Department of Economics, Working Paper 353. 
Schweitzer, Maurice E. and Rachel Croson, 1999. Curtailing deception: The impact of direct questions on lies and omissions, International Journal of Conflict Management, $10,3: 225-248$.

Searight H. Russell and Taylor Meredith, 2019. Physician deception and telling the truth about medical "bad news": History, ethical perspectives, and cultural issues, In: T. Docan-Morgan (Ed.), The Palgrave Handbook of Deceptive Communication: 647-672.

Spiegelman, Eli, 2020. What are we really teaching them? Testing the socialization of a maximizing mindset, mimeo, Burgundy School of Busieness.

Sutter, Matthias, 2009. Deception through telling the truth?! Experimental evidence from individuals and teams, Economic Journal, 119, 534: 47-60.

Tergiman, C., and Villeval, M. C. 2019. The way people lie in markets. Available at SSRN 3455904.

Vanberg, Christoph, 2008. Why do people keep their promises? An experimental test of two explanations, Econometrica 76, 6: 1467-1480.

Vansteenkiste, Maarten, Bart Duriez, Joke Simons, and Bart Soenens, 2006. Materialistic values and well-being among business students: Further evidence of their detrimental effect, Journal of Applied Social Psychology, 36, 12: 2892-2908.

Vranceanu, Radu and Delphine Dubart, 2019. Deceitful communication in a senderreceiver experiment: Does everyone have a price?. Journal of Behavioral and Experimental Economics, 79: 43-52.

Von Mises, Ludvig, 1949. Human Action: A Treatise on Economics, vol.2, Yale University Press. 


\section{A Appendix}

\section{A.1 Data}

\section{Additional data: gender comparison}

\begin{tabular}{|l|l|l|l|}
\hline & Age & Altruism $(0-1)$ & Risk tolerance to $(0-1)$ \\
\hline Male $(\mathrm{N}=146)$ & $19.3(0.27)$ & $0.80(0.03)$ & $0.64(0.02)$ \\
\hline Female $(\mathrm{N}=188)$ & $19.0(0.12)$ & $0.82(0.02)$ & $0.54(0.01)$ \\
\hline Total $(\mathrm{N}=334)$ & $19.15(0.13)$ & $0.81(0.02)$ & $0.58(0.01)$ \\
\hline
\end{tabular}

Table 11: Personal characteristics by gender. (std.err)

No differences in altruism: $\mathrm{p}=0.36$; Difference in tolerance to risk : $\mathrm{p}<0.001$.

\begin{tabular}{|l|l|l|l|}
\hline Condition & $\begin{array}{l}\text { Males } \\
(\mathrm{N}=146)\end{array}$ & $\begin{array}{c}\text { Females } \\
(\mathrm{N}=188)\end{array}$ & $\begin{array}{c}\text { (p-val; two tailed) } \\
\text { diff. between } \mathrm{M} / \mathrm{F}\end{array}$ \\
\hline 1. $T[-1,10]$ & $42 \%$ & $34 \%$ & $(0.15)$ \\
\hline 2. $T[1,10]$ & $67 \%$ & $66 \%$ & $(0.83)$ \\
\hline 3. $T[10,10]$ & $73 \%$ & $80 \%$ & $(0.16)$ \\
\hline 4. $T[1,-5]$ & $36 \%$ & $38 \%$ & $(0.71)$ \\
\hline 5. $T[10,-5]$ & $60 \%$ & $63 \%$ & $(0.64)$ \\
\hline
\end{tabular}

Table 12: Frequency of liars by lie and gender

\section{The results of the survey}

Detail of the answers (all the 7 categories) to the survey on the representative sample of the French population $(\mathrm{N}=1035)$.

S1. An undergraduate student in medicine is more prone to tell black lies compared to an undergraduate student in business administration

S2. An undergraduate student in medicine is more prone to tell white lies compared to an undergraduate student in business administration

S3. In general, the use of black lies is a more frequent practice in the business world compared to the medical world

S4. In general, the use of white lies is a more frequent practice in the business world compared to the medical world 


\begin{tabular}{|l|l|l|l|l|l|l|l|}
\hline & 1. Fully disagree & 2. & 3. & 4. Neutral & 5. & 6. & 7 . Fully agree \\
\hline S1 & $9,1 \%$ & $16,0 \%$ & $11,2 \%$ & $53,9 \%$ & $5,0 \%$ & $2,8 \%$ & $2,0 \%$ \\
\hline S2 & $6,2 \%$ & $8,5 \%$ & $8,2 \%$ & $54,4 \%$ & $12,2 \%$ & $7,3 \%$ & $3,3 \%$ \\
\hline S3 & $4,2 \%$ & $5,4 \%$ & $5,6 \%$ & $41,0 \%$ & $12,2 \%$ & $18,7 \%$ & $12,9 \%$ \\
\hline S4 & $11,9 \%$ & $15,6 \%$ & $8,9 \%$ & $44,2 \%$ & $8,5 \%$ & $6,9 \%$ & $4.0 \%$ \\
\hline
\end{tabular}

Table 13: Opinions on lying differences

Survey executed by OpinionWay, French representative sample, July 2, 2020. 


\section{A.2 Instructions for the Sender}

\section{Introduction.}

Welcome to this short experiment.

Please read these instructions carefully. You may earn a considerable sum of money, depending on the decisions you make in the experiment. The amounts in euro are presented here below. At the end we'll chose one in 20 participants and pay them in cash at the end of the experiment (no later than 2 weeks from now on).

You will be matched at random with another participant that will take his/her decision in a second stage. The other subject is a student in a different higher education institution. His/her identity will not be revealed to you, and he/she will not know who you are. All answers will be traded with the highest degree of privacy.

At the end of the form there is a 4 digit ticket. The number was generated at random. Please keep it, the ticket will help us call the subjects for the payment in this same room, after two weeks. The payment is executed in cash, and privately.

From now on, please stay focus and don't talk to each other.

\section{The main task}

Before starting this experiment, we have rolled a 6 -sided die, and obtained the outcome 2. The other participant will not be informed that the outcome of the die roll was 2. However, he or she will be told that you have been informed about the outcome of the die roll. There are five different payment possibilities. Only you will be informed of the particular monetary values in each payment option. The other participant will not be informed of these monetary values. However, he or she will be told that you have been informed of these monetary values.

At the end of the experiment, we will choose one of these payment possibilities at random for actual payment. 
For each of the payment possibilities, we now ask you to send a message to the other participant. The message will correspond to a number from 1 to 6 . There are six possible messages:

Message 1: "The outcome from the roll of the 6-sided die is $1 . "$

Message 2: "The outcome from the roll of the 6-sided die is 2."

Message 3: "The outcome from the roll of the 6-sided die is 3."

Message 4: "The outcome from the roll of the 6-sided die is 4."

Message 5: "The outcome from the roll of the 6-sided die is 5."

Message 6: "The outcome from the roll of the 6-sided die is 6."

Your message will be shown to the other participant, and then he or she will be asked to choose a number between 1 and 6 .

The choice of the number by the other participant will determine the payments in the experiment.

Payment possibility \#1

- If he or she chooses the actual outcome of the roll of the dice, 2 , then you will receive $\$ 20$ and he or she will receive $\$ 20$.

- If he or she chooses a number different than the actual outcome, you will receive $\$ 19$ and he or she will receive $\$ 30$.

The message I will send in this payment option is

"The outcome from the roll of the 6 -sided die is

(Please fill in a number from 1 to 6. )

Payment possibility \#2

- If he or she chooses the actual outcome of the roll of the dice, 2 , then you will receive $\$ 20$ and he or she will receive $\$ 20$. 
- If he or she chooses a number different than the actual outcome, you will receive $\$ 21$ and he or she will receive $\$ 30$

The message I will send in this payment option is

"The outcome from the roll of the 6 -sided die is

(Please fill in a number from 1 to 6.$)$

Payment possibility \#3

- If he or she chooses the actual outcome of the roll of the dice, two, then you will receive $\$ 20$ and he or she will receive $\$ 20$.

- If he or she chooses a number different than the actual outcome, you will receive $\$ 30$ and he or she will receive $\$ 30$.

The message I will send in this payment option is

"The outcome from the roll of the 6 -sided die is

(Please fill in a number from 1 to 6.$)$

Payment possibility \#4

- If he or she chooses the actual outcome of the roll of the dice, 2 , then you will receive $\$ 20$ and he or she will receive $\$ 20$.

- If he or she chooses a number different than the actual outcome, you will receive $\$ 21$ and he or she will receive $\$ 15$.

The message I will send in this payment option is

"The outcome from the roll of the 6 -sided die is

(Please fill in a number from 1 to 6. )

Payment possibility \#5

- If he or she chooses the actual outcome of the roll of the dice, 2 , then you will receive $\$ 20$ and he or she will receive $\$ 20$. 
- If he or she chooses a number different than the actual outcome, you will receive $\$ 30$ and he or she will receive $\$ 15$

The message I will send in this payment option is

"The outcome from the roll of the 6 -sided die is

\section{Complementary tasks}

The main task is over now, you can move to the complementary tasks. You have received a sealed envelope. You can open it now and read the additional instructions.

Please indicate us: your gender $\mathrm{M} / \mathrm{F}$

Please indicate us: your age

Thinking of yourself, do you think you are fully prepared to take risks? Answer on this scale, from 0: "not at all", to 10: "fully prepared".

012345678910 .

Please open now the envelope.

This last task is completely unrelated to the previous tasks.

If you are one of those chosen for payment, you obtained 10 more euros. You can chose to share it with a charity, to be selected at random from the list of these seven charities. We will transfer the funds at the end of the experiment.

- $\quad$ Les Restos du Cour

- $\quad$ La Fondation Abbé Pierre

- $\quad$ Secours Populaire

- $\quad$ Action contre la faim

- Apprentis d'Auteuil

- $\quad$ Comité Français pour l'Unicef

- $\quad$ Greenpeace 
Please circle the amount you want to give: 012345678910 euros. 


\section{I \\ ESSEC \\ BUSINESS SCHOOL}

ESSEC Business School

3 avenue Bernard-Hirsch

CS 50105 Cergy

95021 Cergy-Pontoise Cedex

France

Tel. +33 (0)134433000

www.essec.edu

\section{ESSEC Executive Education}

CNIT BP 230

92053 Paris-La Défense

France

Tel. +33 (0)1 46924900

www.executive-education.essec.edu

\section{ESSEC Asia-Pacific}

5 Nepal Park

CONTACT:

Singapore 139408

RESEARCH CENTER

Tel. +65 68849780

research@essec.edu

\section{www.essec.edu/asia}

ESSEC | CPE Registration number 200511927D

Period of registration: 30 June 2017 - 29 June 2023

Committee of Private Education (CPE) is part of SkillsFuture Singapore (SSG)

\section{ESSEC Africa}

Plage des Nations - Golf City

Route de Kênitra - Sidi Bouknadel (Rabat-Salê)

Morocco

Tel. +212 (0)537824000

www.essec.edu 